\title{
Stability of Class II treatment with the Bionator followed by fixed appliances
}

\author{
Manoela Fávaro FRANCISCONI, José Fernando Castanha HENRIQUES, Guilherme JANSON, Karina Maria Salvatore \\ de FREITAS, Patrícia Bittencourt Dutra dos SANTOS
}

Department of Pediatric Dentistry, Orthodontics and Community Health, Bauru School of Dentistry. University of São Paulo, Bauru, SP, Brazil.

Corresponding address: Manoela Fávaro Francisconi - Departamento de Ortodontia - Faculdade de Odontologia de Bauru, Universidade de São Paulo Alameda Octávio Pinheiro Brisolla, 9-75 - Bauru - SP - 17012-901 - Phone/Fax: +55 14 3235-8000 - +55 14 $3235-8217$ - e-mail: manuff@usp.br

Submitted: January 7, 2013 - Modification: July 16, 2013 - Accepted: September 11, 2013

\section{ABSTRACT}

\begin{abstract}
$\mathrm{O}$ bjective: This prospective study assessed the stability of Class II treatment with the Bionator, followed by fixed appliances, 10 years after treatment. Material and methods: The experimental group comprised 23 patients of both sexes (10 boys, 13 girls) at a mean initial age of 11.74 years (late mixed or early permanent dentitions), treated for a mean period of 3.55 years who were evaluated at three stages: initial (T1), final (T2) and longterm posttreatment (T3). A total of 69 lateral cephalograms were evaluated and 69 dental casts were measured using the PAR index. The difference between initial and final PAR indexes, the percentage of occlusal improvement obtained with therapy and the percentage of relapse were calculated, using the PAR index. The variables were compared by repeated measures analysis of variance (ANOVA) followed by Tukey tests. Results: The significant improvement in apical base relationship, the palatal inclination of the maxillary incisors and the labial inclination of the mandibular incisors, and the significant improvement in molar relationship and reduction of overjet and overbite, obtained with treatment, remained stable in the long-term posttreatment period. There was also significant improvement in the occlusal relationships which remained stable in the long-term posttreatment period. The percentage of occlusal improvement obtained was of $81.78 \%$ and the percentage of relapse was of $4.90 \%$. Conclusions: Treatment of Class II division 1 malocclusions with the Bionator associated with fixed appliances showed to be stable in the long-term posttreatment period.
\end{abstract}

Key words: Orthodontics. Recurrence. Malocclusion. Angle Class II. Functional orthodontic appliances.

\section{INTRODUCTION}

The combined use of functional and fixed appliances for treatment of certain malocclusions, in determined periods of the growth, can generate greater outcomes than that achieved by the use of functional or fixed appliances separately. Orthodontists should, therefore, consider this possibility when dealing with multiple factors that determine a malocclusion ${ }^{19}$.

After its introduction in 1964, the Bionator has been the object of several investigations aimed to identify both the dentoalveolar and skeletal effects of this appliance. Most studies dealt with short-term outcomes of Bionator therapy by using various types of control groups (untreated Class I or Class II subjects) $)^{1,3,14}$.
In general, correction of Class II, division 1 by combined orthopedic-orthodontic therapy is related to skeletal and dental factors. Retraction and uprighting of the maxillary incisors, associated with proclination of the mandibular incisors; increase in mandibular molar eruption; no skeletal modification of the maxilla and favorable increase in total mandibular length have been consistently described in cases treated with the Bionator ${ }^{16}$. However, these changes can be considered satisfactory only if they remain stable. Longitudinal studies show that changes achieved with active treatment tend to undergo relapse toward the original malocclusion in the years following the end of orthodontic treatment ${ }^{27}$. The relationship between teeth and bone bases does not necessarily remain constant over the years, but can often be changed during 
growth. It is possible that many orthodontic relapse cases represent only the results of an unfavorable posttreatment growth ${ }^{27}$. In addition, bucofacial muscles exert a great influence on the development of the face and teeth. After the correction of Class II malocclusion, the final disposition of the teeth is a reflection of the result of the interaction of hard and soft tissues ${ }^{2}$. Many orthodontists believe that is possible to prevent relapse by positioning teeth in harmony with the lips, cheeks and tongue; eliminating harmful habits, using appropriate retention and establishing a favorable occlusion ${ }^{11}$.

Therefore, because stability is known to be the fundamental key to the successful outcome of orthodontic treatment, this prospective study investigated stability of the occlusal and dentoskeletal changes 10 years after treatment with the Bionator, followed by fixed appliances.

\section{MATERIAL AND METHODS}

This study was approved by the Ethics in Research Committee of Bauru School of Dentistry, and all subjects signed informed consent.

The sample size was calculated based on an alpha significance level of 0.05 and a beta of 0.2 to achieve $80 \%$ of power to detect a mean difference of $0.5^{\circ}$ with a standard deviation of $0.5^{\circ}$ in ANB angle change between the posttreatment and long-term posttreatment stages ${ }^{10}$. The sample size calculation showed that 9 patients were needed, and to increase the power even more it was decided to select 23 patients for the experimental group.

Therefore, 69 lateral cephalometric headfilms and dental casts of 23 Class II division 1 malocclusion patients (10 male; 13 female) who were treated with Balters' Bionator followed by fixed appliances, were collected from the files of the Orthodontic Department at Bauru School of Dentistry, University of São Paulo.

The sample was selected according to the following inclusion criteria: in the late mixed or early permanent dentitions; at least half-cusp bilateral Class II molar relationship and $5 \mathrm{~mm}$ of overjet; absence of agenesis, supernumerary or lost teeth; convex profile; without history of previous orthodontic treatment ${ }^{30}$. No cephalometric characteristic was considered as inclusion criteria.

The treatment protocol consisted of Class II correction with the Bionator during a mean period of 1.52 years (S.D. $=0.79$, range from 0.41 to 3.08 years) (Table 1 ) constructed with coverage of the mandibular incisors (Figure 1 ), followed by a mean period of 1.76 years (S.D. $=0.94$, range from 0.56 to 4.45 years) (Table 1 ) of fixed appliance therapy, after correction of the Class II anteroposterior discrepancy, for leveling and alignment of the teeth and to refine the occlusion. In all cases,

Table 1- Mean, standard deviation (SD), minimum and maximum values of the ages at T1, T2 and T3 and of the treatment with the Bionator, fixed appliance, and both (T1-T2) and long-term posttreatment (T2-T3) periods

\begin{tabular}{ccccc}
\hline & Mean & Minimum & Maximum & SD \\
\hline T1 age & 11.74 & 9.92 & 14.42 & 1.30 \\
T2 age & 15.38 & 13.00 & 19.50 & 1.69 \\
T3 age & 24.99 & 18.83 & 32.92 & 3.37 \\
Bionator period & 1.52 & 0.41 & 3.08 & 0.79 \\
\hline Fixed Appliance period & 1.76 & 0.56 & 4.45 & 0.94 \\
\hline T1-T2 period & 3.55 & 1.08 & 7.33 & 2.14 \\
\hline T2-T3 period & 9.91 & 5.00 & 17.42 & 3.66 \\
\hline
\end{tabular}

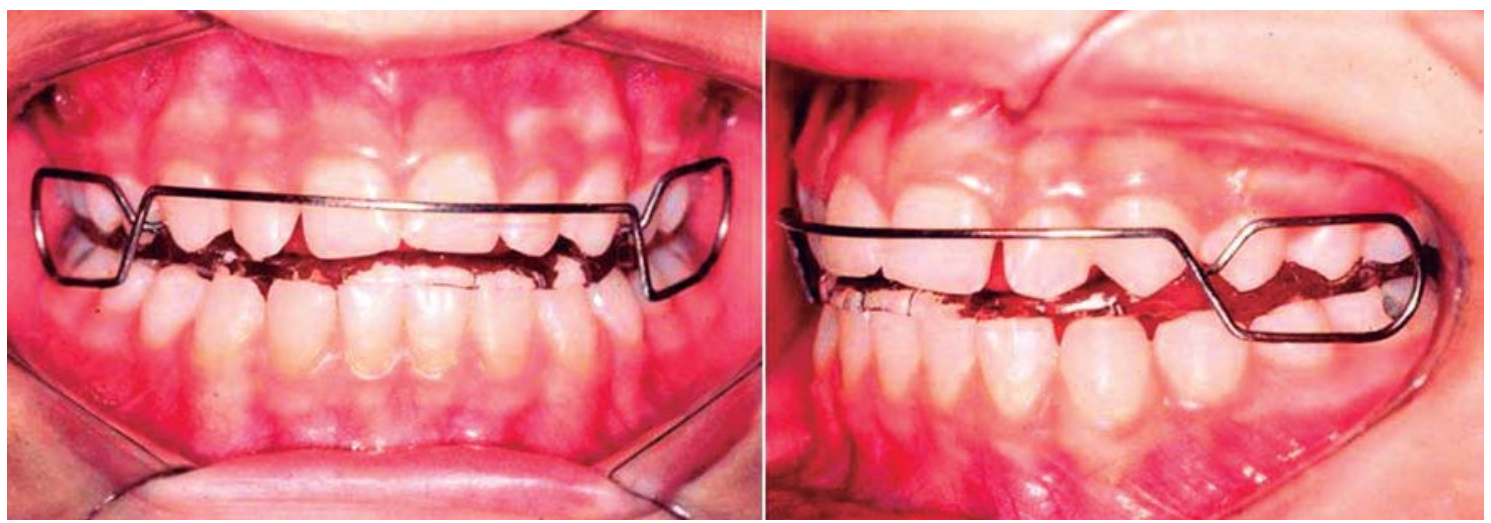

Figure 1- Balters' Bionator with coverage of the mandibular incisors 
after correction with the Bionator, active retention was made with Class II intermaxillary elastics. After comprehensive treatment, each patient was given a fixed mandibular canine-to-canine retainer and a Hawley plate. Maxillary removable Hawley retainers were worn all day long for 6 months and only during sleeping for additional 6 months, and mandibular fixed canine-to-canine retainers were used for a minimum period of five years or until the end of growth.

The patients were evaluated at three stages (Table 1): initial (T1), final (T2), and long-term posttreatment (T3). The mean initial age was 11.74 years (S.D. $=1.30$, range 9.92 to 14.42 ), the mean final age was 15.38 years (S.D. $=1.69$, range 13.00 to 19.50 years) and the mean age at the long-term posttreatment stage was 24.99 years (S.D. $=3.37$, range 18.83 to 32.92 years). All patients were treated non-extraction for a mean period of 3.55 years (S.D.=2.14; range 1.08 to 7.33 years).
As this research aimed to investigate treatment stability, the selected subjects had to have been out of treatment for five years, at least. The mean long-term posttreatment period was 9.91 years (S.D. $=3.66$, range 5.00 to 17.42 years).

The anatomic tracing and location of dentoskeletal landmarks were manually carried out by a single investigator (M.F.F.) and digitized (Numonics AccuGrid XNT, model A30TL.F - Numonics Corporation, Montgomeryville, Penn, USA). These data were then stored in a computer and analyzed with Dentofacial Planner 7.2 (Dentofacial Planner Software Inc., Toronto, Ontario, Canada). This software also corrected the magnification factor ( $6 \%$ and $9.8 \%$ ) of the radiographic images and calculated the angular and linear cephalometric variables employed in this study. The unusual cephalometric variables are illustrated in Figures 2 and 3 .

The peer assessment rating (PAR) index ${ }^{23}$ was

\begin{tabular}{l}
\hline LAFH $(\mathrm{mm})$ - Linear distance between ANS and Me points (ANS anterior nasal spine, Me menton point). \\
\hline S-Go $(\mathrm{mm})$ - Linear distance between S and Go points (S sella point, Go gonion point). \\
\hline 1-NA (mm)- Linear distance between the most anterior point of maxillary central incisor and the NA line. \\
\hline 1.NA $\left(^{\circ}\right)$ - Angle formed by the maxillary incisor long axis and the NA line. \\
\hline 1-NB $(\mathrm{mm})$ - Linear distance between the most anterior point of mandibular central incisor and the NB line. \\
\hline 1.NB $\left(^{\circ}\right)$ - Angle formed by the mandibular incisor long axis and the NB line. \\
\hline $\begin{array}{l}\text { Nasolabial angle }\left(^{\circ}\right) \text { - Angle formed by the Prn'-Sn line and UL-Sn' line (Prn' pronasal point, Sn subnasal point, UL upper } \\
\text { lip). }\end{array}$
\end{tabular}

Figure 2- Definitions of abbreviations of unusual cephalometric variables used ${ }^{12,18,24,28}$

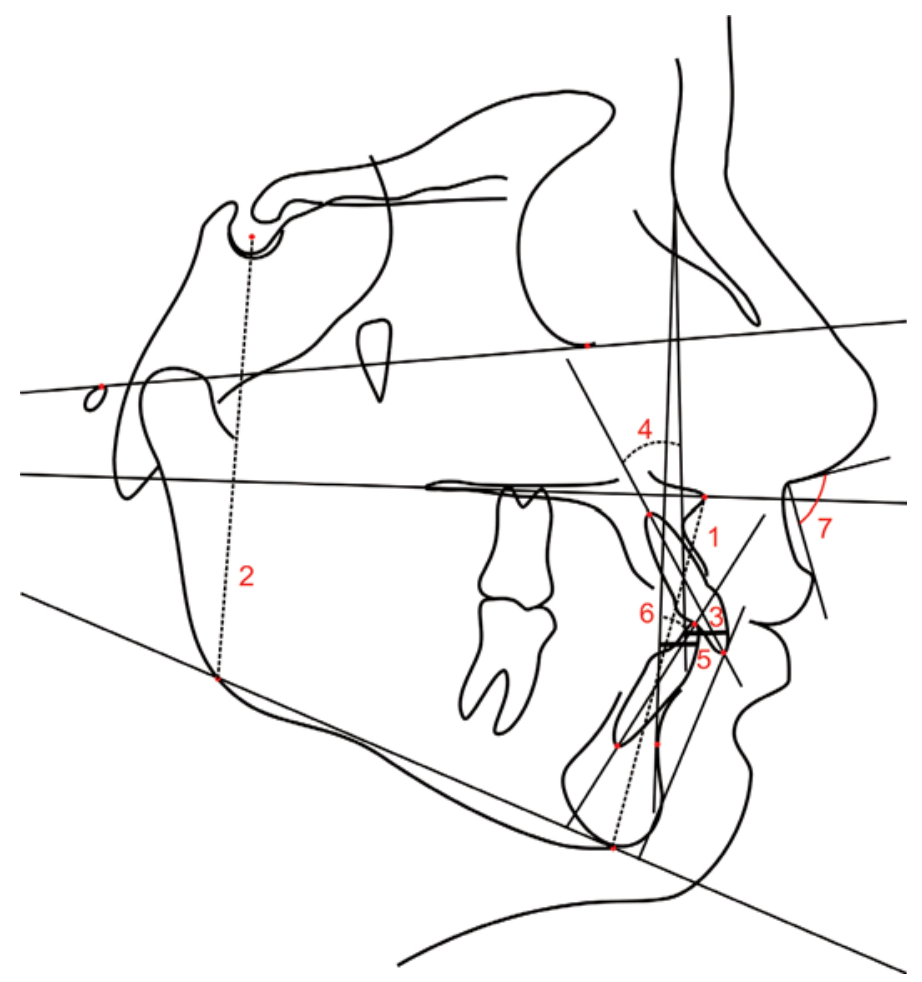

Figure 3- Cephalometric variables: 1) LAFH; 2) S-Go; 3) 1-NA; 4) 1.NA; 5) 1-NB; 6) 1.NB; 7) Nasolabial angle 
calculated on the dental casts of each patient according to the American weightings suggested by De Guzman, et al. ${ }^{6}$ (1995). The index was ranked by scores for molar and premolar anteroposterior $(A P)$ relationship, overjet (OJ), overbite (OB), crowding and midline to quantify the initial malocclusion severity (PAR1), the treatment occlusal results (PAR2), the occlusal status at the long-term posttreatment stage (PAR3), the amount of treatment (PAR1-PAR2) and longterm posttreatment changes (PAR3-PAR2) and the percentage of PAR treatment and long-term posttreatment changes 6,23 , which are better estimates of the occlusal changes ${ }^{10}$.

\section{Error study}

Twenty four lateral cephalograms and dental casts were randomly selected, retraced, redigitized, and remeasured by the same examiner (M.F.F.) after a 30-day interval. Casual and systematic errors were calculated comparing the first and second measurements with Dahlberg's formula ${ }^{5}$ and dependent t-tests, respectively, at a significance level of $5 \%$.

\section{Statistical analyses}

Normal distribution was evaluated with Kolmogorov-Smirnov tests. Because all variables showed normal distribution, repeated measures ANOVA, followed by Tukey tests were used to compare the variables at the three stages. The statistical tests were performed with Statistica software (Statistica for Windows 6.0; Statsoft, Tulsa, Okla, USA). Results were considered significant for $P<0.05$.

\section{RESULTS}

Only 3 (SN.GoGn, S-Go and 6-PP) of the 16 evaluated variables showed statistically significant systematic errors, and no variable showed casual errors greater than $1.0 \mathrm{~mm}$ or $1.5^{\circ}$.

There were no significant changes in the maxillary component with treatment, but there was significant increase in the effective maxillary length in the longterm posttreatment period (Table 2 ). Treatment

Table 2- Comparison of the cephalometric variables at the three stages (repeated measures ANOVA followed by Tukey tests)

\begin{tabular}{|c|c|c|c|c|}
\hline Variable & Initial (T1) & Final (T2) & Long-term PT (T3) & $\mathbf{P}$ \\
\hline & Mean (SD) & Mean (SD) & Mean (SD) & \\
\hline \multicolumn{5}{|c|}{ Maxillary Skeletal Component } \\
\hline $\operatorname{SNA}\left({ }^{\circ}\right)$ & $82.59(2.75)^{A}$ & $81.63(2.74)^{A}$ & $82.10(3.43)^{\mathrm{A}}$ & 0.180 \\
\hline Co-A (mm) & $81.51(4.26)^{A}$ & $82.83(5.40)^{A}$ & $86.05(4.10)^{\mathrm{B}}$ & $0.000^{*}$ \\
\hline \multicolumn{5}{|c|}{ Mandibular Skeletal Component } \\
\hline $\operatorname{SNB}\left({ }^{\circ}\right)$ & $76.85(3.24)^{A}$ & $78.63(3.20)^{\mathrm{B}}$ & $79.16(3.88)^{\mathrm{B}}$ & $0.000^{*}$ \\
\hline Co-Gn (mm) & $99.64(4.79)^{A}$ & $107.81(6.75)^{\mathrm{B}}$ & $112.07(6.32)^{\mathrm{C}}$ & $0.000^{*}$ \\
\hline \multicolumn{5}{|c|}{ Maxillomandibular Relationship } \\
\hline ANB $\left(^{\circ}\right)$ & $5.68(2.72)^{A}$ & $3.01(2.42)^{B}$ & $2.93(2.73)^{\mathrm{B}}$ & $0.000^{*}$ \\
\hline \multicolumn{5}{|l|}{ Facial Pattern } \\
\hline SN.GoGn $\left({ }^{\circ}\right)$ & $30.52(4.89)^{A}$ & $30.47(6.47)^{\mathrm{A}}$ & $28.43(6.96)^{\mathrm{B}}$ & $0.008^{*}$ \\
\hline \multicolumn{5}{|l|}{ Vertical Component } \\
\hline LAFH (mm) & $58.32(4.72)^{A}$ & $62.92(5.09)^{\mathrm{B}}$ & $64.70(6.28)^{\mathrm{c}}$ & $0.000^{*}$ \\
\hline S-Go $(\mathrm{mm})$ & $66.55(4.94)^{A}$ & $73.27(6.58)^{\mathrm{B}}$ & $77.20(7.77)^{\mathrm{C}}$ & $0.000^{*}$ \\
\hline \multicolumn{5}{|c|}{ Maxillary Dentoalveolar Component } \\
\hline 1-NA (mm) & $5.41(2.76)^{A}$ & $4.96(2.74)^{A}$ & $5.04(2.95)^{A}$ & 0.706 \\
\hline 1.NA $\left(^{\circ}\right)$ & $31.94(6.04)^{\mathrm{A}}$ & $27.68(6.56)^{\mathrm{B}}$ & $26.84(7.14)^{\mathrm{B}}$ & $0.000^{*}$ \\
\hline \multicolumn{5}{|c|}{ Mandibular Dentoalveolar Component } \\
\hline 1-NB (mm) & $3.37(2.40)^{\mathrm{A}}$ & $5.53(2.46)^{\mathrm{B}}$ & $5.00(2.38)^{\mathrm{B}}$ & $0.000^{*}$ \\
\hline 1.NB $\left({ }^{\circ}\right)$ & $26.40(5.66)^{\mathrm{A}}$ & $31.06(5.71)^{\mathrm{B}}$ & $29.16(5.83)^{\mathrm{AB}}$ & $0.002^{*}$ \\
\hline \multicolumn{5}{|l|}{ Dental Relationships } \\
\hline Molar Rel. (mm) & $1.17(1.93)^{A}$ & $-3.27(0.61)^{\mathrm{B}}$ & $-2.95(0.46)^{\mathrm{B}}$ & $0.000^{*}$ \\
\hline Overjet (mm) & $8.61(2.34)^{A}$ & $3.22(0.70)^{B}$ & $3.80(1.17)^{\mathrm{B}}$ & $0.000^{*}$ \\
\hline Overbite (mm) & $4.17(1.84)^{\mathrm{A}}$ & $2.27(0.97)^{\mathrm{B}}$ & $2.78(1.10)^{\mathrm{B}}$ & $0.000^{*}$ \\
\hline \multicolumn{5}{|l|}{ Soft tissue Component } \\
\hline Nasolabial angle $\left({ }^{\circ}\right)$ & $109.79(9.45)^{A}$ & $112.01(11.92)^{A}$ & 110. $06(10.42)^{A}$ & 0.523 \\
\hline
\end{tabular}

*Significant at $\mathrm{P}<0.05 ; \mathrm{SD}=$ Standard Seviation 
Table 3- Comparison of the occlusal statuses at the three stages (repeated measures ANOVA followed by Tukey tests)

\begin{tabular}{ccccc}
\hline Variable & Initial (T1) & Final (T2) & Long-term Posttreatment (T3) & P \\
& Mean (SD) & Mean (SD) & Mean (SD) & \\
\hline PAR & $30.13(5.90)^{\mathrm{A}}$ & $5.39(3.39)^{\mathrm{B}}$ & $5.60(4.55)^{\mathrm{B}}$ & $0.000^{*}$ \\
\hline
\end{tabular}

*Significant at $\mathrm{P}<0.05 ; \mathrm{SD}=$ Standard Seviation

Table 4- Results of the peer assessment rating (PAR) index changes during treatment and during the long-term posttreatment period

\begin{tabular}{ccc}
\hline Variable & Mean & SD \\
\hline IPAR - FPAR & 24.73 & 6.64 \\
long-term PAR - FPAR & 0.21 & 2.62 \\
Percentage of PAR treatment changes & $81.78 \%$ & 11.26 \\
Percentage of PAR long-term posttreatment changes & $4.90 \%$ & 12.26 \\
\hline
\end{tabular}

$\mathrm{PAR}=$ peer assessment rating; $\mathrm{SD}=$ Standard Deviation

produced a significant increase in mandibular protrusion and in the effective mandibular length, which also significantly increased in the long-term posttreatment period. These changes contributed to a significant improvement in apical base relationship, which remained stable. The facial pattern angle remained stable with treatment but significantly reduced in the long-term posttreatment period. There were significant increases in anterior and posterior face heights with treatment and in the long-term posttreatment period. The maxillary incisors presented a significant palatal inclination and remained stable afterwards. The mandibular incisors presented significant labial inclination and protrusion which remained stable afterwards. Treatment also produced significant improvement in molar relationship and reduction of overjet and overbite, which remained stable in the long-term posttreatment period.

There was significant reduction of the PAR index during treatment which remained stable in the long-term posttreatment period (Table 3). The percentage of occlusal improvement obtained with treatment was $81.78 \%$ and the percentage of occlusal relapse was $4.90 \%$ (Table 4 ).

\section{DISCUSSION}

\section{Sample and methodology}

Even though the Bionator has been part of routine functional appliance therapy for nearly four decades, surprisingly few methodologically sound clinical studies of this treatment approach, at least by today's standards, have appeared in the orthodontic literature ${ }^{3,14}$. Although several cephalometric investigations on the short-term treatment effects of the Bionator appliance in growing subjects with Class II malocclusion have been published ${ }^{3,14,26}$, no previous research has dealt with the issue of long-term response to this type of therapy. Since stability is known to be the fundamental key to successful outcome of orthodontic treatment, this prospective study investigated the stability of dentoskeletal changes 9.91 years after treatment with Balters' Bionator, followed by fixed appliances. Consequently, the results are due to several effects of the Balters' Bionator associated with fixed appliances.

The absence of a control group is a shortcoming of the present study. Nevertheless, relevant information can still be obtained in the long-term posttreatment period.

\section{Maxillary component}

There were no significant changes in any of the two variables used to evaluate the maxillary component between the initial (T1) and final (T2) stages (Table 2). These results are in agreement with previous studies that also found no significant restriction of maxillary growth with Bionator treatment ${ }^{3,14}$. Only changes in the effective maxillary length showed a statistically significant increase in the long-term posttreatment stage, which were possibly consequent to normal growth and development.

\section{Mandibular component \\ A statistically significant increase in mandibular protrusion and length was observed during treatment, which is in agreement with the results of a number of investigations involving the Bionator/ activator appliance ${ }^{1,3,8,14}$ (Table 2). Mandibular length continued to significantly increase in the posttreatment period probably consequent to normal growth. This can contribute to stability of Class II relationship correction, but it did not contribute to further significant increase in mandibular protrusion.}


Maxillomandibular relationship

The maxillomandibular relationship showed significant improvement during treatment and remained stable in the long-term posttreatment period (Table 2). Improvement in basal bone relationship during treatment resulted from the significant mandibular growth and protrusion, as previously discussed. Similar findings were obtained with the Bionator/activator therapy ${ }^{1,29}$. Most important is that the maxillomandibular relationship achieved with Bionator treatment remained stable in the long-term posttreatment period, similarly to non-extraction Class II malocclusion treatment with other appliances ${ }^{22}$.

\section{Facial pattern}

The mandibular plane angle was unaffected during treatment ${ }^{17}$, while in the long-term posttreatment period it experienced a counterclockwise rotation. Growth that usually takes place in the long-term posttreatment period is characterized by mandibular counterclockwise rotation in response to vertical redirection of condylar growth ${ }^{20}$ (Table 2 ).

\section{Vertical component}

Lower anterior face height and posterior face height significantly increased during treatment and in the posttreatment period (Table 2). Usually, during treatment with a functional appliance they significantly increase more than a control group and this is regarded as an effect of these appliances ${ }^{3,13}$. However, the significant increase in the posttreatment period can only be regarded as consequent to normal growth and development?

\section{Maxillary dentoalveolar component}

The maxillary incisors were palatally tipped during treatment and remained stable in the long-term posttreatment period (Table 2). Palatal movement of the maxillary incisors with the use of the Bionator associated to fixed appliances has already been described in several studies which showed that almost all functional appliances produce palatal tipping of the maxillary incisors ${ }^{3,9,14,22}$.

There was stability of the sagittal position of the maxillary incisors as observed in the longterm posttreatment stage, which is similar to nonextraction treatment with other appliances ${ }^{9,13,22}$.

\section{Mandibular dentoalveolar component}

Proclination of the mandibular incisors was produced by the Bionator associated to fixed appliances treatment and remained stable at the long-term posttreatment stage (Table 2). The proclination effect is probably consequent to the resultant mesial force on the mandibular incisors induced by mandibular protrusion. This finding corroborates the results of previous reports ${ }^{14}$. It is interesting to notice that even if some proclination of the mandibular incisor occurs in non-extraction Class II malocclusion treatment, it is able to remain stable, as also observed with other treatment modalities $9,13,22$.

\section{Dental relationships}

There was significant molar relationship correction with treatment, which remained stable at the long-term posttreatment stage ${ }^{21}$ (Table 2). Many studies showed the same treatment effects and stability with other orthopedic appliances ${ }^{15}$.

There was decrease in the overjet during treatment and no significant relapse was observed during the long-term posttreatment stage (Table 2). Probably, stability of the sagittal changes of the maxillary and mandibular incisors contributed to stability of the overjet correction. Reduction of the overjet was reported in several studies considering appliances with similar mode of action ${ }^{3,9,15,22}$. Overjet correction was obtained mainly by palatal movement of the maxillary incisors, proclination of mandibular incisors and mandibular normal growth ${ }^{9}$.

The overbite significantly decreased during treatment and remained stable at the long-term posttreatment stage ${ }^{21}$ (Table 2). Similar findings were obtained with other functional appliance therapies ${ }^{15}$.

\section{Soft tissue component}

Despite the significant dentoskeletal changes to correct Class II malocclusion with the Bionator, there was no significant change in the nasolabial angle ${ }^{17}$. This has also been observed with other functional appliances ${ }^{15}$. Consequently, there was also stability of the nasolabial angle in the posttreatment period, as observed with other functional appliances ${ }^{15,22}$ as well as with other non-extraction treatment modalities $^{8}$.

\section{Occlusal results}

The analysis of the dental casts showed that the values of the PAR index presented a statistically significant reduction with an excellent outcome ${ }^{4}$, and remained stable at the long-term posttreatment stage (Table 3 ). There are few studies in the literature evaluating the long-term posttreatment period through the PAR index ${ }^{31}$.

According to final PAR categories suggested by Richmond, et al. ${ }^{23}$ (1992), when the value obtained at the end of treatment is equal to or less than 5 , the occlusion can be considered to be almost perfect. Patients finished the orthodontic treatment with an average PAR of 5.39, and remained stable (average PAR of 5.60) in the long-term posttreatment period (Table 3). This shows that their occlusions were close to ideal in most patients even 10 years after 
the end of treatment.

The percentage of occlusal improvement obtained with this therapy was of $81.78 \%$, which is above the value suggested by Richmond, et al. ${ }^{23}$ (1992) and De Guzman, et al. ${ }^{6}$ (1995), of 70\% and $65 \%$, respectively (Table 4 ). In agreement with these results, Rodriguez, Hirschheimer and Vigorito $^{25}$ (2001) found $55.4 \%$ of improvement using only the Bionator in Class II division 1 malocclusion treatment, showing its efficacy in growing patients.

The percentage of relapse obtained with this therapy was of $4.90 \%$ implying that stability can be achieved with this type of orthopedic-orthodontic treatment, as with other functional appliances $3,9,15,22$ (Table 4).

\section{CONCLUSIONS}

Treatment of Class II division 1 malocclusions with the Bionator associated to fixed appliances showed to be stable in the long-term posttreatment period.

\section{REFERENCES}

1- Almeida MR, Henriques JF, Almeida RR, Almeida-Pedrin RR, Ursi W. Treatment effects produced by the Bionator appliance. Comparison with an untreated Class II sample. Eur J Orthod. 2004;26:65-72.

2- Bass NM. Dento-facial orthopaedics in the correction of class II malocclusion. Br J Orthod. 1982;9:3-31.

3- Bolmgren GA, Moshiri F. Bionator treatment in Class II, division 1. Angle Orthod. 1986;56:255-62.

4- Burden DJ, McGuinness N, Stevenson M, McNamara T. Predictors of outcome among patients with class II division 1 malocclusion treated with fixed appliances in the permanent dentition. Am J Orthod Dentofacial Orthop. 1999;116:452-9.

5- Dahlberg G. Statistical methods for medical and biological students. New York: Interscience; 1940.

6- De Guzman L, Bahiraei D, Vig KW, Vig PS, Weyant RJ, O'Brien K. The validation of the Peer Assessment Rating index for malocclusion severity and treatment difficulty. Am J Orthod Dentofacial Orthop. 1995;107:172-6.

7- Derringer K. A cephalometric study to compare the effects of cervical traction and Andresen therapy in the treatment of Class II division 1 malocclusion. Part 1 - Skeletal changes. Br J Orthod. 1990;17:33-46.

8- DeVincenzo JP. Changes in mandibular length before, during, and after successful orthopedic correction of Class II malocclusions, using a functional appliance. Am J Orthod Dentofacial Orthop. 1991;99:241-57.

9- Drage $\mathrm{KJ}$, Hunt NP. Overjet relapse following functional appliance therapy. Br J Orthod. 1990;17:205-13.

10- Dyken RA, Sadowsky PL, Hurst D. Orthodontic outcomes assessment using the peer assessment rating index. Angle Orthod. 2001;71:164-9.
11- Gottlieb EL. Relapse. J Clin Orthod. 1971;5:417-8.

12- Holdaway RA. A soft-tissue cephalometric analysis and its use in orthodontic treatment planning. Part I. Am J Orthod. 1983;84:1-28.

13- Janson G, Caffer DC, Henriques JF, Freitas MR, Neves LS. Stability of Class II, division 1 treatment with the headgearactivator combination followed by the edgewise appliance. Angle Orthod. 2004;74:594-604.

14- Janson I. A cephalometric study of the efficiency of the bionator. Trans Europ Orthod Soc. 1977;28:283-98.

15- Küçükkeleş N, Ilhan I, Orgun IA. Treatment efficiency in skeletal Class II patients treated with the jasper jumper. Angle Orthod. 2007;77(3):449-56.

16- Lange DW, Kalra V, Broadbent BH Jr., Powers M, Nelson S. Changes in soft tissue profile following treatment with the bionator. Angle Orthod. 1995;65:423-30.

17- Maltagliati LA, Henriques JF, Janson G, Almeida RR, Freitas MR. Influence of orthopedic treatment on hard and soft facial structures of individuals presenting with Class II, Division 1 malocclusion: a comparative study. J Appl Oral Sci. 2004;12:164-70.

18- McNamara JA Jr. A method of cephalometric evaluation. Am J Orthod. 1984;86:449-69.

19- Miguel JA, Cunha DL, Calheiros AA, Koo D. Rationale for referring Class II patients for early orthodontic treatment. J Appl Oral Sci. 2005; 13:312-7.

20- Monini AC, Gandini Júnior LG, Martins LP, Raveli DB. Longitudinal study on skeletal changes during and after bionator therapy using metallic implants. Braz J Oral Sci. 2010;9:33-8.

21- Oltramari PV, Conti AC, Navarro RL, Almeida MR, AlmeidaPedrin RR, Ferreira FP. Importance of occlusion aspects in the completion of orthodontic treatment. Braz Dent J. 2007;18:78-82. 22- Pancherz $\mathrm{H}$. A cephalometric analysis of skeletal and dental changes contributing to Class II correction in activator treatment. Am J Orthod. 1984;85:125-34.

23- Richmond S, Shaw WC, O'Brien KD, Buchanan IB, Jones $R$, Stephens $C D$, et al. The development of the PAR Index (Peer Assessment Rating): reliability and validity. Eur J Orthod. 1992;14:125-39.

24- Ricketts RM. A four-step method to distinguish orthodontic changes from natural growth. J Clin Orthod. 1975;9:208-15,21828.

25- Rodriguez GC, Hirschheimer C, Vigorito JW. Transversal changes of the dental arches following bionator therapy in growing patients with class II-1 malocclusion. Ortodontia. 2001;34:36-42. 26- Rudzki-Janson I, Noachtar R. Functional appliance therapy with the Bionator. Semin Orthod. 1998;4:33-45.

27- Sinclair PM, Little RM. Dentofacial maturation of untreated normals. Am J Orthod. 1985;88:146-56.

28- Steiner CL. Cephalometrics as a clinical tool. Philadelphia: Lea \& Fabiger; 1962.

29- Tulloch JF, Phillips C, Koch G, Proffit WR. The effect of early intervention on skeletal pattern in Class II malocclusion: a randomized clinical trial. Am J Orthod Dentofacial Orthop. 1997; 111:391-400.

30- Wheeler TT, McGorray SP, Dolce C, Taylor MG, King GJ. Effectiveness of early treatment of Class II malocclusion. Am J Orthod Dentofacial Orthop. 2002;121:9-17.

31- Woods M, Lee D, Crawford E. Finishing occlusion, degree of stability and the PAR index. Aust Orthod J. 2000;16:9-15. 